\title{
Section 8 orders on the public-private law divide
}

Article

Accepted Version

Harding, M. and Newnham, A. (2017) Section 8 orders on the public-private law divide. Journal of Social Welfare and Family Law, 39 (1). pp. 83-101. ISSN 1469-9621 doi:

https://doi.org/10.1080/09649069.2016.1177256 Available at https://centaur.reading.ac.uk/67096/

It is advisable to refer to the publisher's version if you intend to cite from the work. See Guidance on citing.

To link to this article DOI: http://dx.doi.org/10.1080/09649069.2016.1177256

Publisher: Taylor \& Francis Group

All outputs in CentAUR are protected by Intellectual Property Rights law, including copyright law. Copyright and IPR is retained by the creators or other copyright holders. Terms and conditions for use of this material are defined in the End User Agreement.

\section{www.reading.ac.uk/centaur}

\section{CentAUR}

Central Archive at the University of Reading

Reading's research outputs online 


\title{
Section 8 orders on the public-private law divide
}

Corresponding author:

Contributing author:

Dr. Annika Newnham (University of Reading)

\author{
Dr. Maebh Harding (University of Warwick) \\ maebh.harding@warwick.ac.uk.
}

The fieldwork for this article was carried out while both authors were senior lecturers at the University of Portsmouth.

This work was supported by the Nuffield Foundation under grant CPF/40293. This project is funded by the Nuffield Foundation, but the views expressed are those of the authors and not necessarily those of the Foundation.

\begin{abstract}
While section 9 (2) of the Children Act 1989 prevents a Local Authority from applying for a child arrangements order directly, a case file study of residence and contact orders made in $2011^{1}$ found that a significant number of applications for residence orders in the County Court were supported and sometimes even instigated by local authority children's services. The findings of the study demonstrate that residence orders often form part of solutions offered to the family and can even operate as an alternative to formal public law remedies in situations where the parents are no longer able to provide care, and grandparents or other relatives take over. In these hybrid cases private law orders are used to resolve situations on the fringes of public law action and, in some cases, divert cases from voluntary accommodation or formal care proceedings. This article raises questions about whether cases are being diverted to private law remedies in an appropriate manner and argues that closer scrutiny of the practice is required to ensure that the rights of parents, children and kinship carers are appropriately respected.
\end{abstract}

\section{Introduction}

There are many different examples of child law applications which bridge the private- public law divide. One child in a family may be the subject of private law proceeding while a sibling is the subject of care proceedings. The court may order a section 37 report in a section 8 application the findings of which lead to care and supervision orders being made in later proceedings. Formal care proceedings may end, not with a care order but with a residence order (now known as a child

1 M Harding \& A Newnham, “How do County Courts share the care of children between parents?' (2015) available online at : http://www.nuffieldfoundation.org/sites/default/files/files/Full\%20report.pdf 
arrangements order). ${ }^{2}$ Care proceedings may also end in a negotiated agreement for a child to remain in the care of the other parent or a relative and that person may later apply for a section 8 order to add security to the outcome. A private law residence or contact application may be running in parallel with a section 47 investigation in relation to the same child. The allegation under investigation is often at the heart of the residence or contact dispute. Bainham argues that private law cases with public law elements are an increasingly common phenomenon in the courts. ${ }^{3}$ This trend may be set to increase as current family policy which promotes private agreement and has rendered legal aid for section 8 applications very difficult to obtain ensures that court is a last resort for parents and only the most difficult disputes reach the courts.

This article examines local authority involvement in applications for orders under section 8 of the Children Act 1989. The total population is made up of a retrospective sample of 197 case files from five different County Courts which exited the court system between February and August 2011. There was evidence of local authority involvement in 56 case files. The level of involvement ranged from passively providing the court with information to actively driving the process as an alternative to or the result of public child protection proceedings.

The use of section 8 orders in hybrid cases is an under-explored area ${ }^{4}$ and the findings of this article challenge the prevailing depiction of section 8 orders as a purely private law remedy. Section 8 orders are routinely used to place children with non-parent carers in situations where public law remedies would otherwise be necessary. The use of section 8 orders to regulate kinship care has been observed by Hunt and Waterhouse ${ }^{5}$ who found that $25 \%$ of kinship care cases were formalised by a residence order. In 2013 Selwyn et al found even higher numbers of residence orders in their sample: $56 \%$ of kinship care arrangements were formalised by a residence order. ${ }^{6}$ Official statistics also record the numbers of children who exit 'looked after' status because a section 8 order is made in any given year. In 2011, $4 \%$ of the children who exited 'looked after' status did so because a section 8 residence order was made. 7 Such statistics do not record the numbers of children who never acquired 'looked after' status because a private law order was made. Masson, Dickens et al found that about a quarter of cases in which children's services had commenced a formal 'preproceedings process' did not enter care proceedings. Three out of the 34 cases examined which were diverted to kinship or family care became subject to private law proceedings. ${ }^{8}$

The role of the court in public proceedings and private proceedings under the Children Act 1989 is very different. There are limitations on the court's discretion in proceedings under Part IV of the Children Act; the local authority makes the decision of whether or not to apply for a care order and has autonomy over the care plan and implementation of the care plan. In private law proceedings, the court has a full range of discretionary powers but may not make a public law order. The court is

2 In J Masson et al, Care Profiling Study (2008) it was found that residence orders were made in $23 \%$ of care applications. In $73.5 \%$ of these cases the court also made a supervision order.

3 A Bainham, 'Private and public children law; an under explored relationship' (2013) 25 CLFQ 138, 139

4 For critical commentary see N Wall, 'The courts and child protection - the challenge of hybrid cases' (1997) 9 CFLQ 345; A Bainham, 'Private and public children law; an under explored relationship' (2013) 25 CLFQ 138 and N Arnold 'A state of flux' [2008] New Law Journal 698-699.

5 J Hunt \& S Waterhouse, Understanding Family and Friends Care: the relationship between need, support and legal status - Carers' experiences (Family Rights Group/Oxford University Centre for Family Law and Policy 2012).

6 J Selwyn and others, The Poor Relations? Children and Informal Kinship Carers Speak Out (Buttle 2013).

7 Department of Education, Children looked after by local authorities in England: year ending 31 March 2011 Statistical First Release SFR 21/2011, https://www.gov.uk/government/statistics/children-looked-after-bylocal-authorities-in-england-year-ending-31-march-2011 accessed 22nd December 2014.

8 J Masson, J Dickens et al, Partnership by Law: The pre-proceedings process for families on the edge of care proceedings (2013), 151 
powerless to go beyond requiring the authority to investigate and make a section 37 report. Where there is evidence in private law proceedings of an inconclusive local authority investigation, tensions between the role of the court and the role of local authority arise. Wall argues that judicial discretion can be fettered in such cases to a degree that gives rise to genuine anxiety. ${ }^{9}$ Bainham suggests that where a local authority participates in private law proceedings but does not issue proceedings itself this amounts to a judgment that its concerns have not reached the level required to cross the public law threshold. ${ }^{10}$

In the sample examined, two different types of hybrid case are identified. In 'hybrid solution' cases the application for a private law order was made at the instigation of a private individual but because of ongoing local authority involvement with the family, the private order formed part of a local authority managed solution for the family. In 'diversion cases' the application was made on the advice or insistance of the local authority. In these cases the local authorities were encouraging or at least endorsing a private law order as an alternative to care proceedings or voluntary accommodation.

The priority for the local authority in all of these cases is to ensure that children are receiving appropriate care. In many of the diversion cases the established primary caregiver could no longer care for the child due to severe mental health issues or drug and alcohol abuse. Using a section 8 order to divert cases from care proceedings or voluntary accommodation is cost effective for the local authority avoiding both the cost of issuing proceedings and the cost of long-term substitute care. Placement of a looked after child within the extended family is now a statutorily required preference, ${ }^{11}$ and private orders allow the same end result to be achieved. Diversion to private law also minimises formal state intervention into the family. However, promoting the use of private law orders to ensure that a child is moved from the care of an unsuitable parent raises a number of questions about party representation and consent within the process. In addition, the characterisation of such matters as private law issues rather than public law issues may have the effect of limiting the support and funding available to the child and the new carer.

Wall argues that many of the problems raised in hybrid cases are procedural and can be resolved by good case management and inter agency co-operation between the court, local authorities and police. He suggests that it is the court's duty to take a proactive role in such cases to ensure that any ongoing local authority investigation is coordinated with and runs in tandem to private law proceedings. ${ }^{12}$ He also advocates tightly drawn orders for directions and the effective use of section 7 reports to require the local authority to report on the nature progress and outcome of its child protection proceedings.

Bainham argues that the high instance of hybrid cases and the involvement of local authorities in private cases requires a reappraisal of the court's powers. He raises the spectre of inconsistency of local authority practice which could result in some serious cases going the 'private route' while public law proceedings are used for less serious cases. He suggests that there is an argument to be made that the court should have powers to direct an authority to seek a public law $\operatorname{order}^{13}$ or to require a threshold of harm to be surmounted where the dispute is between a parent and a nonparent. $^{14}$

\footnotetext{
9 N Wall, 'The courts and child protection - the challenge of hybrid cases' (1997) 9 CFLQ 345, p10

10 A Bainham, 'Private and public children law; an under explored relationship' (2013) 25 CLFQ 138, 150.

11 Children Act 1989 s22C brought in by the Children and Young Persons Act 2008

12 N Wall, 'The courts and child protection - the challenge of hybrid cases' (1997) 9 CFLQ 345, p9

13 A Bainham, 'Private and public children law; an under explored relationship' (2013) 25 CLFQ 138, 156.

14 Ibid 158.
} 
The separation of private and public child law issues in reform proposals is long entrenched. ${ }^{15}$ The Family Justice Review ${ }^{16}$ had separate chapters on private and public law. Reforms to the private child law process following the Family Justice Review rest on the assumption that such orders are used to resolve disputes between parents of equal bargaining status over how to share care. ${ }^{17}$ Such individuals are to be dissuaded from going to court by the introduction of mandatory MIAMS ${ }^{18}$ and an emphasis in the new Child Arrangements Programme on non-court resolution. ${ }^{19}$ Such reforms do not take into account the relatively common use of private law orders as part of local authority support to the family or as a diversion from formal public law remedies; cases in which encouraging the parties to go to mediation and minimising court scrutiny may be harmful to the child. Recent cuts to legal aid $^{20}$ are considered justified in private child law cases, which were generally not considered to be complex. However, such cuts were deemed to be inappropriate in public child law cases. ${ }^{21}$ Legal aid is still available in private law cases following LASPO where there is objective evidence of a risk of abuse to the child from another party to the proceedings. ${ }^{22}$ This includes evidence that the child is the subject of a child protection plan and that the risk identified comes from the other party to the proceedings. Legal aid will not be available to a parent accused of neglect and may be difficult to obtain where the risk to the child comes from a third party (for example where a grandmother is taking over care because of a mother's new violent boyfriend). Such a distinction between the availability of legal aid in private and public law proceedings is objectionable in section 8 cases which cannot be characterised as purely private remedies. It is argued that parties in such hybrid cases will be detrimentally affected by recent changes to the Family Justice system which amplify existing problems of representation; these cases may also potentially be pushed into the public law system.

\section{Local Authority involvement in section 8 applications}

In the sample of 197 cases, evidence of local authority involvement with the family was found in 56 cases; $28 \%$ of the total population. This subpopulation of 56 cases can be divided into three categories based on the role played by the local authority in the section 8 proceedings.

\section{Providing information}

In $23 \%$ of cases the local authority played a passive role, merely providing information to the court upon request, usually in the form of a section 7 report. In these cases local authority children's services had little interest in the outcome in private law proceedings either because its involvement with the family was historic or because the outcome in the proceedings would make no difference to the ongoing support provided to the family.

Local authority children's services rather than CAFCASS may be asked to produce the relevant welfare report where the court is made aware of previous local authority involvement with the

15 Bainham notes that in the 1980s reform proposals of private and public law were initially separate exercises carried out by separate bodies, ibid 138.

16 Family Justice Review: Final Report (MoJ 2011) \& The Government Response to Family Justice Review : A system with Children and Families at its Heart, $\mathrm{cm} 8273$ (TSO 2012)

17 The Government Response to Family Justice Review : A system with Children and Families at its Heart, $\mathrm{cm}$ 8273 (TSO 2012)p18.

18 Mediation Information and Assessment Meetings were made compulsory by s10 of the Children and Families Act 2014.

19 Practice Direction 12(B):(CAP 2014).

20 Legal Aid, Sentencing and Punishment of Offenders Act 2012.

21 MoJ, Reform of Legal Aid in England and Wales: the Government Response cm 8072 (2011).[45]-[51].

22 Ibid [27]-[30] see also Legal Aid Agency, The Legal Aid, Sentencing and Punishment of Offenders Act (LASPO) 2012 - Evidence Requirements for Private Family Law Matters (2014).[3.1]-[3.44]. 
family. ${ }^{23}$ In such cases the local authority is in a better position than CAFCASS to provide information. For example, in B15 the local authority were directed to file a section 7 report because they had provided support to the mother for mental health issues.

In other cases children's services became involved for the first time during the private law application because of child safety concerns raised during CAFCASS's section 7 inquiries or a later incident. For example in D27 the child alleged in interviews with CAFCASS that Mum had hit him with a belt. A section 47 investigation was carried out. The allegations were not substantiated and CAFCASS resumed its reporting duties.

In some of these cases it appeared that the parents themselves had unnecessarily involved social services, making false or malicious referrals where there were no safeguarding concerns, in order to give weigh to their allegations against the other parent. For example, in C45 the father had reported the mother to the police several times for physically harming the children and also involved social services. She had reported to social services that the children had demonstrated sexualised behaviour following contact with their father. None of the allegations were substantiated and there were no safeguarding concerns. Social services had advised the parents that they were not responsible for sorting out contact issues but they continued to make counter claims against each other.

\section{Hybrid solutions}

In $28 \%$ of cases the local authority took a more active in resolving some of the families' issues providing support services, managing supervised contact and entering into safeguarding agreements with the family. Whether or not the family engaged with support services appeared to exert a major influence on the outcome of private law proceedings.

For example, in B8 the child was living with maternal grandparents in accordance with a residence order made 2 years previously. The parents (who were living together and had younger children) applied for a residence order. The local authorities assessed both the parents and the grandmother. The case turned on engagement with local authority support. Mum and dad engaged with parenting classes and alcohol support whereas the grandmother was struggling with her own children's behaviour and had not engaged well with support services. The court made a family assistance order and eventually after a great deal of interim contact a residence order was made for the parents.

In all of these cases the outcome of the private law proceedings became part of a 'hybrid solution' to help these families. The private court orders made reinforced agreements with local authorities and sometimes expressly made contact dependent on continued co-operation.

For example, in B28, a father's application for contact, the local authority was involved with the family due to the father's violent behaviour and school attendance issues of the mother's other children with a different father. Following a child protection conference the children were made subject of a child protection plan. Social services asked both parents to sign a written agreement to prevent interaction between mum and dad at contact handovers and required the contact to be supervised. The court ordered interim contact in compliance with the agreement. Dad was referred

\footnotetext{
${ }^{23}$ See CAFCASS \& ADCS Good Practice Guidance: determining whether Cafcass or a local authority should prepare a section 7 report available http://www.adcs.org.uk/download/goodpractice/cafcass/Good\%20Practice\%20Guidance\%20\%20determining\%20whether\%20Cafcass\%20or\%20a\%20local\%20authority\%20should\%20prepare\%20a\%2 Osection\%207\%20report.pdf See also CAFCASS and ADCS 'Protocol For Allocating Responsibilities For Court Reporting In Private Law Children Act 1989 Proceedings Between CAFCASS And Local Authority Children's Services' (2010) available http://adcs.org.uk/download/position-statements/aug-10/adcs-cafcass-protocolfor-allocation-repsonsibilities-final-august-2010.pdf.
} 
to a living without violence programme. A final agreement was reached with social services as to contact arrangements and this was made into the final contact order.

Some of these cases started as purely private law cases but children's services became involved due to child protection concerns raised during the application. For example in B7, a father's application for contact, following the introduction of interim contact the child returned with a black eye and the mother reported the incident to social services. It was concluded that was an accidental injury caused during play with a step sibling and dad agreed in writing with child services to supervise contact more closely in future. Mum then made further allegations of physical abuse and the father blamed the injuries on the mother. The unexplained injuries were investigated by social services but the investigations were inconclusive. The child was made the subject of a child protection plan and there were ongoing child protection visits to the child's home. The child remained living with mum and an order for overnight contact with dad was made.

In B65 social services became involved in a contact dispute when it was disclosed to a mediator that the paternal grandfather was a schedule one sex offender. Contact with dad took place in the paternal grandparents' house. Interim court orders for contact to take place at dad's brother's house were made subject to the approval of children's services. Children's Service carried out an assessment and concluded that the risk to the child was likely to increase as the child grew older. The father was supported to appreciate the risk to the child and attended a course on dealing with child sex offenders and became more aware and accepting of the risk. He agreed to safeguards and supervisions and finally agreed that there should be no future contact with the grandparents. The final contact order was made on the condition that the father would not allow the child any direct or indirect contact with the grandparents.

In some cases the court took a passive role, expressly deferring to social services who put forward the strategy for resolution and actively managed all interim stages before the final order.

In B16 Mum applied to suspend contact with Dad on a temporary basis while social services assessed the situation. Dad made multiple allegations to social services that the children had been assaulted and were suffering neglect over the last number of years. These allegations were investigated and dismissed but the children were made the subject of a child protection plan on the basis of emotional harm. The court made an interim order for contact as arranged by social services. Contact was gradually reintroduced and was progressing well. The court made a 'no-order' order for contact leaving it up to the parties with the support of social services.

The court took a more proactive role to managing the parallel child protection investigation in E39. This case had also started as a private law application. Dad had applied for a residence order claiming that Mum was unable to adequately care for the children, who were exposed to drug and alcohol abuse. Mum denied all the allegations and accused Dad of being a violent drunk. The court was told that there had been a number of referrals and that a core assessment on the family was underway. While these investigations were carried out the court made an order for the child to remain with Dad and to have supervised contact with Mum. This contact was to be supervised by the father's extended family. Following a number of delays in obtaining a section 7 report from social services the court ordered a full section 37 report. Social services supported Dad's application for residence but kept the case open. They had continued involvement with the mother due to concerns over her ability to care for another child with a different father. They also monitored interim contact and continued to assess the suitability of Mum's accommodation which was still of concern when the case exited the court system. The private law orders were only a small part of the solution being put together by the local authority. 


\section{Diversion cases}

In $50 \%$ of casesthe application for a section 8 order was directly initiated by the actions of the local authority. Twelve of these cases were applications for residence by fathers because social services had deemed the mother to be unable to continue to care for the child. Seven similar applications were made by relatives. In all these cases, mothers struggled with addiction and/or mental illness and the child was living with a new carer by agreement with local authority social services. Seven cases involved applications by parents for an order to allow the return of their child to their care following a residence order made for the other parent or a kinship carer on the recommendation of social services. Two cases involved the question of whether fathers should have contact in circumstances where children's services opposed direct contact as a risk to the child. Such cases can be viewed as a diversion to private law from care proceedings or other ongoing child services involvement.

Applicants often mentioned in their application form that they had been advised to apply for the section 8 order because the alternative would be care proceedings. For example in B36, social services were involved due to allegation of violence against dad, substance misuse by mum and concerns about mum's new partner. After a family group conference the child was handed to dad. The local authority told him to apply for a residence order and made it clear that they would otherwise begin care proceedings. A draft agreement for contact had been proposed by Borgate children's services and it was agreed that dad would make child available for contact with mum every Saturday and dad to remain present throughout contact. Children's services confirmed in writing that urgent public law action would have to be taken if the child was returned to her mum.

The trigger for placement with non-parents was maternal inability to care for children in circumstances where the fathers were not seriously considered as substitute primary carers. The files generally provided good reasons for this approach, which was taken by both children's services and the County Courts. For example in C29 the alcoholic father was also suspected of having sexually abused his daughter's older half-sisters. In B41 the father's learning difficulties meant he failed to see why it was so wrong to view child pornography on the internet.

The most common choice of non-parent carer were grandparents. For example in E25 mum had six children. The case was about her 13-year-old son. His two older sisters were living with their maternal grandmother, while his three younger siblings and half-siblings were also living with mum. They were subject to a child protection plan; mum's last two partners had been violent in the home, she often left the children on their own, and social workers suspected that she was suffering depression. Children's services had suggested that the boy move to gran's house, following reports of aggressive behaviour at school. The case was kept under review for six months after the interim move, the boy's behaviour improved and a final residence order was made with reasonable contact to mum.

Some families had struggled with difficulties for months or even years and relatives had already stepped in to ensure that the children were being adequately cared for. ${ }^{24}$

In E16, the 12-year-old boy's move to his aunt and uncle had originally been a temporary one, made permanent by the mother's worsening mental health. There was frequent informal contact and everyone involved (including the boy) was happy for the arrangement to continue. Children's services, who praised the applicants for providing a safe and secure environment, had prompted the residence application because the mother's new partner presented a high risk to the boy and should

24 C30 was the only case of this type where the mother had actually been the child's primary carer prior to the litigation; but she had lived next door to the maternal grandparents and acknowledged that they had played a significant part in the child's daily care. 
not be allowed to have any contact with him. It seemed that everyone involved saw this order as lasting until the boy was old enough to leave home.

Social services took a decisive role in the resolution of these proceedings, managing both interim contact arrangements and sometimes final contact arrangements.

In B41 social services had been involved with the family for some time because both parents had learning difficulties. Dad lived in supported accommodation and mum lived with the maternal grandmother. The need for a residence order arose when Mum met a new boyfriend on the internet and wanted to move taking the child with her. Social services supported the maternal grandmother's application for residence as it would allow consistent and appropriate care for the child and would give gran some legal protection against intervention from the paternal grandparents. They recommended no contact with the father who had been viewing child pornography and could not understand why this was harmful. Both the grandmother and the father made undertakings to social services not to allow contact between dad and child. The court made a residence order and a no contact order.

In C14, the child had initially been placed with the father by agreement with social services due to concerns about her safety with Mum. Dad had applied for a residence order. During the case the nursery reported that the child had a very serious bruise on her groin. The local authority had reserved its position on Dad's application for residence and wanted a period of intensive assessment and work with the family although they did not intend to issue care proceedings at that time. The court noted a highly detailed agreement between Mum and Dad and the local authority care management team. The final court order noted the agreement with social services and made a residence order for Dad and an order for reasonable contact with Mum. Social services continued to monitor the situation and the parents had agreed to co-operate with them and comply with the child protection plan.

The final order in all these 28 cases was consistent with the recommendation of the local authority. All 12 residence applications by fathers were successful. All 7 applications by non-parents for a residence order were also successful. In the seven cases where mothers applied to have their children returned to their care, 3 were successful and 4 were not. An order that there would be no direct contact was made in both cases where the fathers posed a risk to the child.

The mothers successfully engaged with social services support services in three cases where the children were returned to their mothers' care. B43 shows that private orders can be successfully used for resolving issues within troubled families although it may be a slow process. In this case the child had been subject to a child protection plan due to Mum's history of violent relationships and substance abuse. A residence order had been made 3 years prior to the application confirming the child's placement with the maternal grandmother. Since that time Mum had resolved her issues with support from social services, she was now alcohol free and had regular overnight contact. Her application for a residence order was approved by children's services and supported by the maternal grandmother.

Similarly in E2, the mother submitted to blood and liver function tests. She was given a short amount of day contact at the start of the case while the test were being processed. When results came back indicating that mum was still drinking, she scaled back her application from residence to increased contact. An order was made for overnight contact; this went well for six months, and the children said they wanted to go home. The court made an interim residence order to be monitored by the local authority, and five months later the final residence order was made with the support of the local authority. This had been a carefully monitored process,

The level of co-operation of the non-parent carers in these cases was commendable. Not only had they cared for these children for many years but they co-operated with court, Cafcass and/or social 
workers in reinitiating the children's relationships with their mothers and in some cases agreed to transfer primary care while remaining in the background for support.

Considerable efforts had been made in other cases to keep the mothers involved with their children through the use of shared residence orders and supervised contact orders in conjunction with undertakings.

For example in B37 the children had been placed with Dad by the police who had found Mum to be so intoxicated that she was not fit to care for them. Mum declined support from social services. The final order provided for daytime contact only progressing to overnight contact if this went well. Mum gave an undertaking not to drink during contact and both parents undertook not to denigrate each other in the children's presence.

Attempts to keep the mothers involved after a transfer of residence were was not always successful.

In B20, children's services had become involved due to mum's heavy drinking. In previous proceedings the court had made a shared residence order even though the child lived most of the time with the father. Less than 2 years later the father applied for sole residence. The section 7 Report, written by a Borgate social worker, confirmed dad's assertion that shared residence was not working. It noted that 'Whilst it had been hoped that a joint residency [sic] would provide a satisfactory outcome for [the girl] and both parents, the situation appears to have left [her] experiencing instability' and relationships within the family had not improved. Mum was an alcoholic, with a chaotic home. When interviewed, the 10-year-old daughter said: 'it feels like I'm looking after her, it feels like I' $m$ the grown up and she's the child'. There were frequent fights between the mother and her friends; the daughter witnessed these and was sometimes a target for the violence. The section 7 Report also criticised mother's lack of insight into how her drinking and fighting with friends affected her child. At this point in proceedings, the father applied to relocate to another country with the daughter, his new wife and her children and was granted permission to do so.

In the cases where the children were placed with non-parents the level of contact with both mothers and fathers tended to be quite low. The parents in these cases were often struggling with multiple problems. Reliability could be an issue and there were also child safety concerns. These cases were more focussed on finding a safe and stable residence for the child, than on contact as a highly prioritised goal in its own right.

In C29 a neighbour and long-term family friend was required to make the child available for one hour of contact with the troubled mother each Saturday and Sunday. However, no contact order was made for the father: he had not actively sought one, had problems with alcohol abuse, and was under investigation regarding alleged sexual abuse of his daughter or her older half-sisters.

Contact orders were generally not very detailed in such cases; in C1, C4 and E25 the orders were merely for 'reasonable contact'. While they reinforced the principle of contact, they left many of the details up to the non-parent carer. This brought flexibility, but also placed a lot of responsibility on the non-parents' shoulders. In A1 the local authority noted that contact was distressing to the young child as the mother was volatile and self-harming, but also recommended it should be kept up to maintain the little boy's link to his younger half-brother.

\section{Is the application of the private law framework to hybrid cases appropriate?}

$22 \%$ of the overall sample was made up of hybrid solution cases and diversion cases. These cases are far from the paradigm private child law case of parents who can come to their own arrangements. The local authority takes a much more active role and the court may defer to arrangements reached 
between the parties and the local authority instead of purely private agreements reached by the parties themselves. Although the exact nature of the assessment processes taking place were not always clear from the information in the examined files, it appeared that in many cases placing the child with another carer was part of a child protection plan. This involvement of the local authorities in these cases raises questions about the voluntariness of some of the arrangements which are turned into section 8 'consent orders'.

The use of private law orders to divert cases from public law remedies is surely appropriate where parents and carers are in agreement and aware of the legal consequences of the private law order. This channelling of families away from a public law support into private law remedies minimises formal state intervention into the family. The children are removed from the care of an unsuitable parent, to be cared for by their father or a relative with whom they have a pre-existing bond. The residence order provides the new carers with some security by giving them parental responsibility. When providing long term voluntary accommodation to a child, or accommodating a child who is the subject of a care order, the local authority must give preference to relatives, friends or other persons with a previous connection to the child. ${ }^{25}$ Therefore, placing a child with a relative who then applies for a Section 8 residence order can be seen as a cost efficient and less interventionist route to the same outcome. ${ }^{26}$

However, in the cases examined, parents and carers were often unrepresented at court and without legal advice. The choice to utilise a private law order rather than public law remedies may also make a meaningful difference to the level of ongoing support given to parents, children and carers. This section will examine some of the issues raised by these cases and consider whether greater transparency and tighter case management by the court is the solution, as suggested by Wall, or whether, as Bainham suggests, the court should have the power to refer some of these cases to public law proceedings.

\section{Consent, agreement and representation}

Recent changes to the family justice system have prioritised private ordering in section 8 applications and also made it much less easy for private law applicants to obtain legal advice and representation to go to court. These reforms are based on certain assumptions about what private law cases are about. These hybrid cases are not the paradigm private reordering of the family. In most of the hybrid cases in our sample the parents had not lived together at all. Maintaining the autonomy of a previously intact family is not a relevant goal. Neither does it seem appropriate for the mothers in these cases, who were commonly battling mental illness, addiction and other problems, to be persuaded into a transfer of residence without any legal scrutiny of that process.

Public law processes prioritise agreement with the family and the use of the least interventionist solution. Children's services are encouraged to work in partnership with parents even where they are considering public law proceedings. Child protection plans are made by agreement with parents ${ }^{27}$ but the plan may state that if the parents do not agree the local authority will apply for care order. Masson et al found that emergency court proceedings were frequently avoided by obtaining a parent's agreement for the child to be accommodated under section $20 .^{28}$ Masson and Dickens in a study examining the more formal 'pre-proceedings process' for care proceedings found that the pre proceedings process was also used both to avoid care proceedings and agree relative

25 The Children Act 1989, section 22A.

26 Re C (Family Placement) [2009] EWCA Civ 72 [19]

27 Department of Health, Working together to safeguard children: A guide to inter-agency working to safeguard and promote the welfare of children (March 2015).

28 J Masson, D McGovern et al. Protecting Powers: Emergency Intervention for Children's Protection, (Wiley, 2007) 221-222. 
care. ${ }^{29}$ This more formal process was sometimes used to 'step up' the seriousness of concerns to the parents, to encourage them to take the actions required in the plan to improve their parenting. ${ }^{30}$

It is unusual for parents to have legal representation at child protection conferences although they are advised that they may bring an advocate. ${ }^{31}$ Lindley, Richards et al suggest that advocacy services are rare and patchy across the country. ${ }^{32}$ Provision of section 20 accommodation for a child does not require legal advice to be given to the parents. ${ }^{33}$ In contrast, where the formal pre proceeding process has been commenced parents qualify for free legal advice so that they can be accompanied by a lawyer to a pre-proceedings meeting. Masson and Dickens found that at least one lawyer was present in $94 \%$ of the cases in their sample. ${ }^{34}$ However Masson and Dickens acknowledge that the pre-proceedings meeting is not a neutral forum as the meeting is chaired by a social work manager and local authority personnel usually outnumber the parents' side. ${ }^{\prime 35}$

The idea that court orders should be avoided in public law processes if other means can be employed is attributed to the 'trickle down' influence of the no-order principle. This approach may indeed work well but in a minority of cases concerns have been raised about enforced partnerships with social services and the oppressive use of power outside the court process. ${ }^{36}$ Socio-legal research has raised concerns about the balance between voluntariness and compulsion and queried whether 'agreement' obtained in such circumstances is really agreement. ${ }^{37}$ Without legal advice such parents might not understand that they could withhold or withdraw consent to the local authority's plan or that alternatives might be available. ${ }^{38}$

Lawyers and judges have viewed such agreements with suspicion because they are made without court scrutiny. For example, the Children Act Advisory Committee warned that section 20 accommodation agreements should not be regarded as an alternative to an application for a care order because of the risk that the cases might drift. ${ }^{39}$ Holt and Kelly argue that making decisions within administrative rather than judicial settings risks delays and the conflation of the rights of parents and children. ${ }^{40}$ Masson and Dickens argue that as the local authority does not share parental responsibility with parents in section 20 accommodation these problems are over stated; the local authority and its carers are limited to making decisions on day to day matters agreed with the parents. ${ }^{41}$ In contrast, court proceedings may exclude parents from decision making. However, Masson recommends that parents are likely to benefit from independent advice even where they

29 J Masson, J Dickens et al. Partnership by Law? The pre-proceedings process for families on the edge of care proceedings (2013), 105.

30 Ibid, 124.

31 Department of Health, Working together to safeguard children: A guide to inter-agency working to safeguard and promote the welfare of children (March 2015) p41.

32 B Lindley, M Richards and P Freeman, 'Advice and advocacy for parents in child protection cases - what's happening in current practice?',(2001) 13 Child and Family Law Quarterly, 167-195.

33 Section 22(4) (5) of the Children Act 1989 merely requires local authorities to ascertain, and give due consideration to, the wishes and feelings of parents and children before making decisions about children they propose to look after, so far as this is reasonably practicable .

$34 \mathrm{~J}$ Masson, J Dickens et al. Partnership by Law? The pre-proceedings process for families on the edge of care proceedings (2013), 177.

35 Ibid 48

36 J Aldgate, The Children Act Now (TSO, 2001), 51.

37 Eg J Brophy Care proceedings under the Children Act 1989: a research review (TSO, 2006); J Masson et Al, Care Profiling Study (2008); E Harlow and S Shardlow 'Safeguarding children: challenges to the effective operation of core groups' (2006) 11 Child and Family Social Work 65-72.

38 P Freeman and J Hunt Parental Perspectives on Care Proceedings (1998).

39 The Children Act Advisory Committee Final Report June 1997 (Lord Chancellor's Department, 1997) 29-30.

40 K Holt and N Kelly, 'Rhetoric and reality surrounding care proceedings: family justice under strain', (2012) 32 Journal of Social Welfare and Family Law, 155-166.

41 P201 
are in full agreement with the plan for accommodation; and legal advice is essential if pressure to agree is placed on parents, which may make the use of accommodation appear forced. ${ }^{42}$

In our sample many cases had come to court after child protection processes. Although all applications were brought by private individuals it was not always clear if the initiative was really theirs or if they acted under pressure from their local authority. In at least three cases social services confirmed in writing the need for urgent action to avoid child protection proceedings and even paid the applicants' legal costs. We see similar tensions between compulsion and voluntariness in the three cases in Masson and Dickens' study which were diverted from the formal pre proceedings process to private law orders, two of the fathers appeared to have taken the initiative to bring proceedings, but in the third case the local authority insisted the father obtain private law orders and agreed to pay his legal costs. ${ }^{43}$

Had the local authority initiated public law proceedings rather than encouraging a private law application representation of the parent and child would have been provided. In 12 out of the 28 diversion cases one party was unrepresented, usually the mother. The mothers from whom the children were removed were very vulnerable. These unrepresented dysfunctional mothers were also highly unlikely to appeal the decisions. There is a danger that diversion from voluntary care using residence orders could be abused in order to place a child with a relative against parental wishes without reaching the public law threshold of significant harm. The lack of legal representation raises questions about the true voluntariness of some of the consent orders made in these cases.

For example, in $\mathrm{C} 1$ neither the grandparent applicants nor the mother had legal advice but a consent order was reached through a negotiation process monitored by the local authority. The young mum had learning difficulties and it was suggested she may be suffering from post-natal depression. The file showed efforts had been made by social workers to explain the implications of a residence order, but there was only one County Court hearing, which the mother did not attend and sent no legal representation .

In B45, the father applied for contact or residence but was actually seeking to formalise an arrangement where his son had been living with his father and his new wife for 18 months. The mother, who had a diagnosis of mixed personality disorder, had expressed suicidal thoughts and also talked about killing the 8-year-old boy. The mother did not resist the order, and never attended court.

The extent to which the court took it upon itself to investigate the extent of the local authority involvement and whether the mother's consent was genuine differed from court to court. This suggests that in some cases the decisions to use particular private orders in these circumstances are made away from the court, and the transparency of these decisions could become problematic.

In D17 the father applied for residence with the support of Dunam children's services. The file suggested that the mother had underlying drug and mental health issues; the child had been living with the father for nine months and the mother did not oppose the application. The order noted that she was having regular staying contact under an agreement made with Dunam children's services. A residence order for the father was made after one hearing. CAFCASS were unhappy about the lack of detail provided by the local authority as to why this change of residence had been recommended and implemented in the first place.

In C1 the mother did not attend court, was unrepresented and was struggling with mental health difficulties but social services assured the court that they had taken steps to ensure that she

42 P202

43 Masson and Dickins Partnership by Law: The pre-proceedings process for families on the edge of care proceedings (2013).152 - 153. 
understood the proposed plan. In contrast, in C11 and C14 the judge ordered social services to provide a full account to the court of their involvement in the case and required the mother to attend court or confirm in writing that she had consented to the residence application.

When a voluntary arrangement with a local authority is reinforced by a section 8 order some court scrutiny is introduced but it is very different to the type of scrutiny that exists in public law cases. Arnold argues that avoiding care proceedings and replacing them with private law proceedings comes at huge cost for parents and children as the child is not seen as a party to the proceedings, there is no equivalent of care plan scrutiny and the likelihood that parents will get publicly funded legal advice is much less. ${ }^{44}$ Unlike section 20 accommodation, making a residence order can affect parental responsibility by giving parental responsibility to another carer and preventing parents from exercising parental responsibility in relation to where a child should live. The effect of the order may be to sever all ties forever. Some of the resident parents will not be able to maintain contact without support. In reality most of these mothers would play very limited roles in their children's lives, would have few opportunities to exercise PR and could, as they struggled with multiple issues, drift out of their children's lives altogether.

In four cases, the final order for the child to live with a non-parent carer was made without any consent from the mother whatsoever. In 3 of these 4 cases the mothers were not represented. Although it was very clear in these cases that the mothers were not coping well and that the children were better off with the non-parents, the decision which had the effect of removing the child from the mother was made outside the procedural safeguards that apply to public law care proceedings. Such cases do raise issues as to whether the private law standard of 'the best interests of the child' is legally appropriate? Such cases potentially have the effect of removing children from the care of their parents by bypassing the 'significant harm' threshold test ${ }^{45}$ and circumventing the need for parental consent. Bainham ${ }^{46}$ has argued that use of private orders to avoid the threshold potentially violates the rights of both parents and children.

In C29, the mother's barrister successfully resisted a Special Guardianship Order on the grounds that it was 'draconian'; she said it was inconceivable that the court would make a parent subject to an order to prevent the exercise of their parental responsibility without a full framework parenting assessment. A residence order was made in that case. This was the only time we saw records in the files of this kind of argument being made before the County Court.

\section{Diversion to Private orders and inadequate support for families}

Children who have been taken into care or are accommodated by the local authority on a voluntary basis ${ }^{47}$ are 'looked after' children. ${ }^{48} \mathrm{~A}$ local authority has a general duty to safeguard and promote their welfare, ${ }^{49}$ and specific duties to accommodate and maintain them. ${ }^{50}$ In practice, this means that local authority foster parents receive a non-means-tested allowance as well as dedicated financial and other support. Where children are 'looked after' all foster carers must be treated the same, regardless of whether they are related to the child. Such children will have their cases reviewed to ensure that looked after children do not drift when alternative legal arrangements would be more appropriate. ${ }^{51}$ However, children who live with relatives under a residence order ${ }^{52}$

\footnotetext{
44 N Arnold 'A state of flux' [2008] New Law Journal 698-699

45 The Children Act 1989 Section 31(2).

46 A Bainham, 'Private and Public Child Law: an under explored relationship' (2013) CFLQ 138.

47 Under Section 20 of the Children Act 1989.

48 As defined in the Children Act 1989 S22(1)

49 Section 22(3) The Children Act 1989

50 Section 22A \& Section 22B respectively.

51 Care Planning, Placement and Case Review (England) Regulations 2010 (2010 SI 959).
} 
do not have 'looked after' status. ${ }^{53}$ Local authorities are empowered to provide support and assistance, ${ }^{54}$ but only on a discretionary basis; such support is not available in all local authority areas. ${ }^{55}$ This means that for non-parent carers it is generally more beneficial ${ }^{56}$ to be viewed as a local authority foster carer or to apply for a special guardianship order, ${ }^{57}$ rather than opting for a private section 8 order.

Local authorities' budgets are limited. It has been estimated that each child cared for by an informal kinship carer saves the taxpayer between $£ 23,500$ and $£ 56,000$ a year. ${ }^{58}$ As Bainham has observed, the temptation for local authorities to use private orders to avoid public proceedings and the financial duties owed to 'looked after' children is high. ${ }^{59}$ This has been recognised in legislation. ${ }^{60}$ Yet, research has shown that poverty is a problem for many non-parent carers, ${ }^{61}$ and that the diversion into private law leads to lower levels of financial and other help for relatives. ${ }^{62}$

The support provided by social services to fathers to help maintain contact with the mother differed from area to area. In A7 the court ordered that contact would be as directed by social services who insisted that contact should be supervised. In D14 where the child had suffered a violent assault by the mother the local authority refused to support supervised contact because the child was not in care; this was the main point of contention in proceedings.

The continued involvement of children's services with a non - parent carer after the residence order had been made also seemed to vary from area to area. In B8, for example, the court made several family assistance orders in order to keep the Local Authority involved.

Other studies have shown that applicants are not necessarily aware that making a private law order will remove the obligation on the local authority to provide ongoing support when they apply to court. Many carers interviewed by Hunt and Waterhouse reported feeling pushed into private orders and complained that the consequences of the private status had not been set out. ${ }^{63}$ Only one case in our sample showed any awareness of the consequences of a residence order on levels of support.

52 Or now a Child Arrangements Order.

53 In fact, the making of an order for the child to live with a relative ends 'looked after' status: $\operatorname{Re} B$ [2013] EWCA Civ 964; GC v LD \& Ors [2010] 1 FLR 583.

54 Department for Education, Family and Friends Care: Statutory Guidance for Local Authorities (TSO 2010) [3.15]; See also the Children Act 1989, Schedule 1, para 15.

55 R (M) v Birmingham City Council [2008] EWHC 1863 (Admin).

56 A residence order does allow the holder to claim Child Tax Credit.

57 Section 14A of the Children Act 1989. It would which would entitle them to a means-tested special guardianship allowance under Regulation 11, Special Guardianship Regulations 2005

58 J Selwyn and others, The Poor Relations: Children and Informal Kinship Carers Speak Out (Buttle 2013).

59 A Bainham, 'Private and Public Child Law: an under-explored relationship', [2013] CFLQ 138, p141.

60 One reason for the introduction of Sections 22A to s22C into the Children Act by the Children and Young Persons Act 2008 was to prevent local authorities from making private arrangements with relatives or friends in order to avoid their duties to 'looked after' children.

61 J Selwyn and others, The Poor Relations: Children and Informal Kinship Carers Speak Out (Buttle 2013).

62 J Hunt \& S Waterhouse, Understanding family and friends care: the relationship between need, support and legal status - Carers' experiences (Family Rights Group/Oxford University Centre for Family Law and Policy 2012); J Selwyn and others, The Poor Relations: Children and Informal Kinship Carers Speak Out (Buttle 2013).

63 J Hunt \& S Waterhouse, Understanding family and friends care: the relationship between need, support and legal status - Carers' experiences (Family Rights Group/Oxford University Centre for Family Law and Policy 2012). 
As mentioned above, the neighbour in C29 applied for a SGO mid-way through the case partly because the council would then be under a duty to provide financial and other support. ${ }^{64}$

In C4 the paternal grandparents sought a residence order for three grandchildren aged 11, 8 and 4. The applicants had helped to raise them because both parents (who were now separated) had longstanding problems with drugs, and a tempestuous relationship. The children had been living full time with their grandparents for nine months. They had initially been dropped off by police officers who had been called out to mum's house and had been alarmed by the chaotic, dangerous home environment and particularly by the presence of mum's new boyfriend. It was clear that the children were thriving and wanted to stay. A Cladford children's services assessment was included in the County Court file. It stated twice that this was a private law matter and so outside the remit of the local authority. Thus, it was the grandparents' responsibility to negotiate and supervise contact with both parents although the mother's drug use and violent partner meant that children's services would almost certainly have had to step in had the grandparents not done so first. We were concerned that these grandparents, like many others, were asked to take on unsettled children and also supervise contact with chaotic, unreliable and often aggressive parents.

We acknowledge that our files did not always contain a full record of the local authority's involvement with that family. However, the use of private orders as an alternative to public proceedings poses some troubling questions about whether the carers in these cases are made aware of the effects a 'private order' may have on the support that will be available to them in the future. Un-represented non-parent carers may be unaware of the consequences of a residence order which may leave them without recourse to the support to which they would otherwise be entitled.

\section{The stability of section 8 order placements}

When placing a child with a relative or friend using the public law route, ${ }^{65}$ that person must also be approved as a local authority foster parent reaching the National Minimum Standards for Fostering Services. ${ }^{66}$ The Family and Friends Care: Statutory Guidance for Local Authorities ${ }^{67}$ notes that the parenting capacity of kinship carers should be rigorously assessed before they are approved as local authority foster carers. ${ }^{68}$ Characterising the dispute as a private matter often meant that the new non-parent carer was not assessed under this framework. In the cases in our sample, local authority assessments of the non-parent carers did not commonly appear in the files. Some of the non-parent carers were battling their own issues or struggling with other challenging children. There is a danger that diversion from formal voluntary care places the child with a kinship carer who may not be able to cope.

In D25, the mother's propensity for fighting when drunk had resulted in several prison sentences. Children's services had been involved for some time before the 10-year-old boy went to live with his aunt (the mum's sister) and his 4-year-old half-sister moved in with the mother's oldest daughter. While the little girl settled in well, the aunt seemed to be struggling with the boy's challenging behaviour, which for example meant he was on a reduced timetable at school.

64 However, as explained in section Error! Reference source not found., when the mother's barrister raised concerns about restricting her use of PR in this way without a full public child law framework assessment, no SGO was made.

65 Section 22C(12) The Children Act 1989.

66 S22C(12) A good description of the assessment process is found in Department of Education, Family and Friends Care: Statutory Guidance for Local Authorities (TSO 2010) [5.1]-[5.20].

67 Department of Education Family and Friends Care: Statutory Guidance for Local Authorities (TSO 2010).

68 Ibid [5.22] 
The use of a residence order as a long term solution is less stable for the children than special guardianship as the parent may re-emerge a few years later and apply to court to seek residence. The children in these cases had often experienced several moves, and it was difficult to feel confident that their latest move would be their last.

In five cases, the parents sought the return of their children who had been cared for by a non-parent for between two and nine years at the time of application. All five mothers were dealing with complex problems ranging from drug and alcohol abuse to chaotic behaviour partially attributed to a history of violent relationships. In three of these five cases, the children were returned to their parents. In two cases they remained with their non-parent carers. The approach of the courts was to reinitiate contact with the parent, often through supervised contact. Where appropriate, parents were expected to submit to drug and alcohol tests as well as attending parenting courses. Where the parents engaged well with the process, the child was returned to their care. Where the parent disengaged from the court process, the child remained with the non-parent carer but the court made an effort to keep some level of contact going. This is an area which seems highly unsuited to private ordering. Returning the children to their parents was a long process which required regular monitoring by the court and social services or CAFCASS. ${ }^{69}$

In D25, mentioned above, the mother successfully completed both her prison sentence and treatment for her alcohol addiction. She applied for the children to be returned to live with her. While the older daughter was clearly reluctant to return her half-sister to her mother's care (but felt it was the right thing to do), it seemed that the aunt was quite grateful to be relieved of responsibility for the difficult son. The Section 7 report, prepared by the local authority, noted that while the son could benefit from a fresh start in a new school, the daughter was likely to find another move stressful. .

However, there was at this point a Catch-22 situation: the mother wanted her children back, but had no suitable accommodation; yet without dependants she could not be provided with social housing. Dunam County Court made a suspended residence order: the children would remain with their nonparent carers until the mother secured suitable accommodation. This case illustrates the temporary nature of the kinship care arrangements made by private orders, and the close cooperation between the County Court and the local authority that may be necessary to resolve the cases.

\section{Conclusion:}

The case file study sheds light on the common use of section 8 orders to resolve situations which would otherwise be resolved by care proceedings or section 20 accommodation. The role played by the local authority in these cases raises questions about whether the private law process provides an adequate level of court scrutiny for families whose problems straddle the boundary between public and private child law. The consent of parents to such arrangements may be given in the shadow of the alternative of care proceedings. Cases where private law orders have the effect of ending a child's relationship with a parent and placing them with a non-parent carer without the parent's consent raise questions about whether reference to the threshold of significant harm would be appropriate. Carers may be left within inadequate support because of the decision by the local authority to characterise the issue as a private law matter.

Parents and non-parent carers are often unrepresented at court proceedings and potentially also during the child protection process. Recent reforms to family justice will only amplify these issues of representation and consent. Cuts to legal aid will make it very difficult for parents and carers to get legal representation and advice for Child Arrangement Order applications. The push towards private

69 Indeed, in B43 the reason given for not attempting mediation was that the local authority needed to assess the situation before the parties could be given free rein to reach an agreement. 
ordering through mediated agreement seems inappropriate for these types of cases where there is no equality of bargaining position and delays may cause child safety issues. Such families fall squarely into the 'LASPO gap' where the situation is unsuitable for mediation but no legal aid is available.

It is argued that the use of section 8 orders in dealing with child protection issues should be more expressly recognised both in national family policy documents and in reviews of family law reform. It is important that cases are being diverted to private law orders in an appropriate manner. Closer scrutiny of the practice is required to ensure that the rights of parents, children and kinship carers are appropriately respected.

Better processes could be introduced to ensure that parents and carers to whom a section 8 order is suggested are aware of the consequences of this decision. This could be done by an extension of legalised procedures into child protection conferences to ensure that parents and kinship carers are aware of the legal consequences of the agreed action or by encouraging greater judicial scrutiny of section 8 cases arising out of child protection conferences within the Child Arrangements Programme. The extension of legal aid to these cases is surely a necessary measure to ensure that the rights of parents and children are respected and could be justified as a preventative measure to ensure that these types of cases do not enter public law proceedings. 